\title{
Successful endoscopic treatment of Boerhaave syndrome using an over-the-scope clip
}
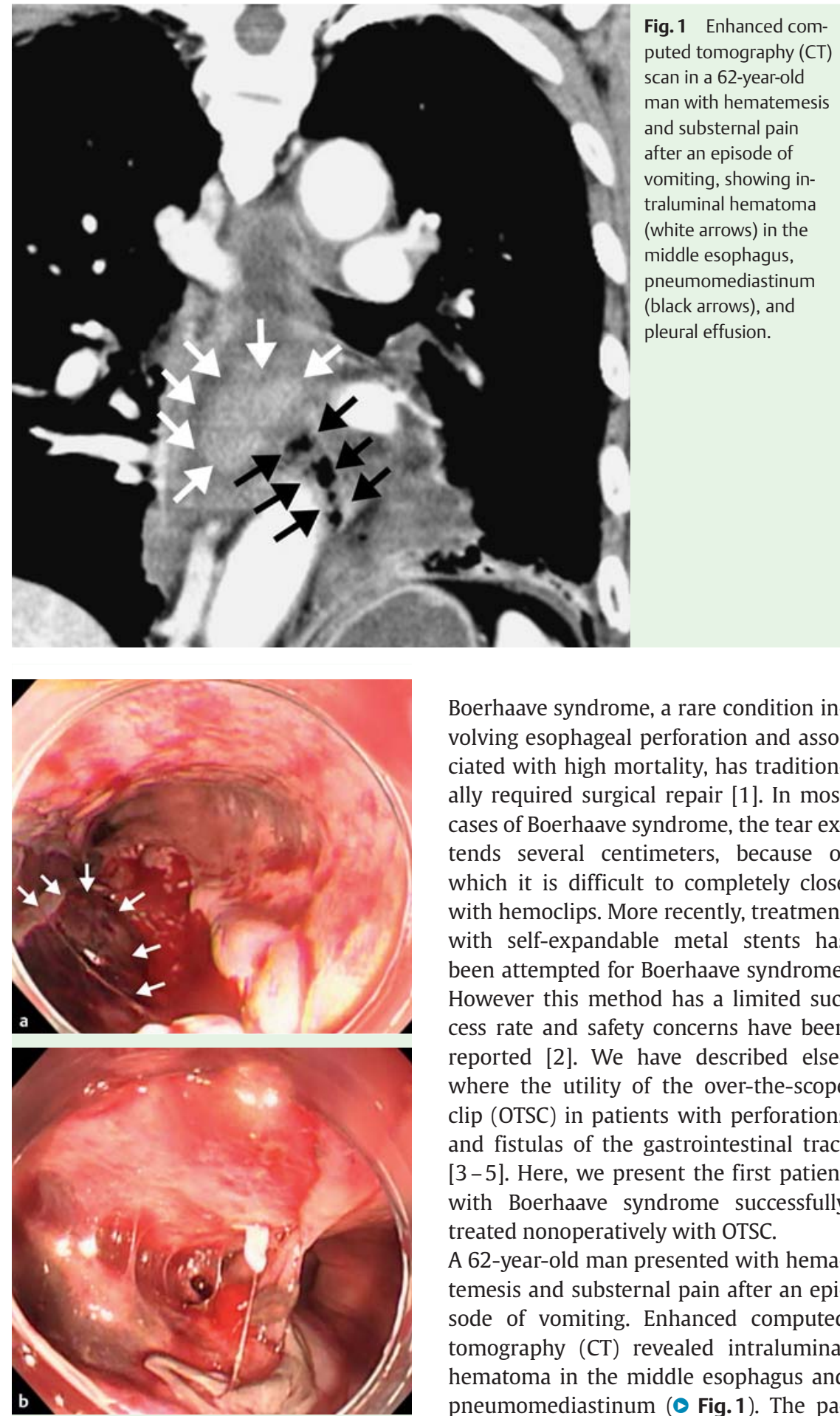

Fig. 2 Endoscopic findings. a There is a $10-\mathrm{cm}$ long tear with hematoma (white arrows) on the left side of middle to lower esophagus. $\mathbf{b}$ The defect with exposed muscularis propria and perforation in lower esophagus.
Boerhaave syndrome, a rare condition involving esophageal perforation and associated with high mortality, has traditionally required surgical repair [1]. In most cases of Boerhaave syndrome, the tear extends several centimeters, because of which it is difficult to completely close with hemoclips. More recently, treatment with self-expandable metal stents has been attempted for Boerhaave syndrome. However this method has a limited success rate and safety concerns have been reported [2]. We have described elsewhere the utility of the over-the-scope clip (OTSC) in patients with perforations and fistulas of the gastrointestinal tract [3-5]. Here, we present the first patient with Boerhaave syndrome successfully treated nonoperatively with OTSC.

A 62-year-old man presented with hematemesis and substernal pain after an episode of vomiting. Enhanced computed tomography (CT) revealed intraluminal hematoma in the middle esophagus and pneumomediastinum ( $\mathbf{F i g . 1}$ ). The patient was diagnosed as having Boerhaave syndrome with spontaneous esophageal perforation. The patient declined surgical repair, and we carried out endoscopic treatment after obtaining informed con-

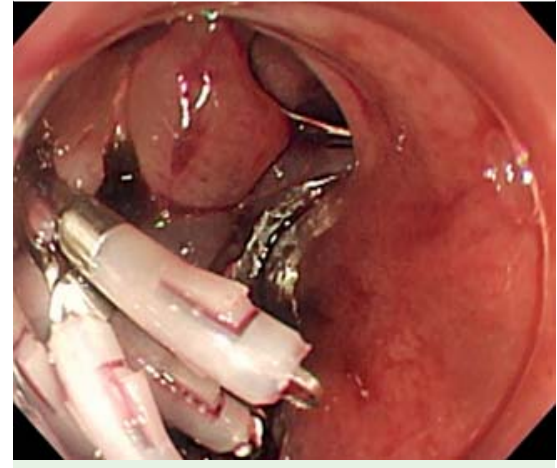

Fig. 3 Endoscopic view showing successful closure of the defect : use of an over-the-scope clip (OTSC) sealed the defect in the lower esophagus, following which the rest could be sealed with hemoclips.

sent. Endoscopy revealed a $10-\mathrm{cm}$ long tear on the middle to lower esophagus and exposed muscularis propria with perforation in lower esophagus ( Fig. 2 and - Video 1). Closure using hemoclips failed because of the extended length of the tear. Another attempt was made to close the tear in the lower esophagus using OTSC, which was successful. Subsequently, owing to the reduction in the length of the tear by using OTSC, we could easily close the defect in the middle esophagus with hemoclips, resulting in successful closure of the whole tear ( Fig. 3 and $\bullet$ Video 1 ). A CT scan taken 2 days after the treatment revealed disappearance of pneumomediastinum ( Fig.4). The clinical condition of the patient improved and he was discharged 25 days later. On follow-up endoscopy 24 days later, the tear site was completely healed with the scarring ( $\bullet$ Fig.5). Our patient had an excellent outcome with complete healing of the defect with-

\section{Video 1}

A view of the $10-\mathrm{cm}$ long tear with hematoma and the site of perforation in lower esophagus is followed by control of active bleeding with hemostatic forceps and unsuccessful closure with hemoclips. The video then shows removal of the hemoclips and use of the twin grasper in the over-the-scope clip (OTSC) system followed by release of the OTSC. Lastly, the tear site is shown being sealed easily with hemoclips, leading to successful closure of the overall defect. 


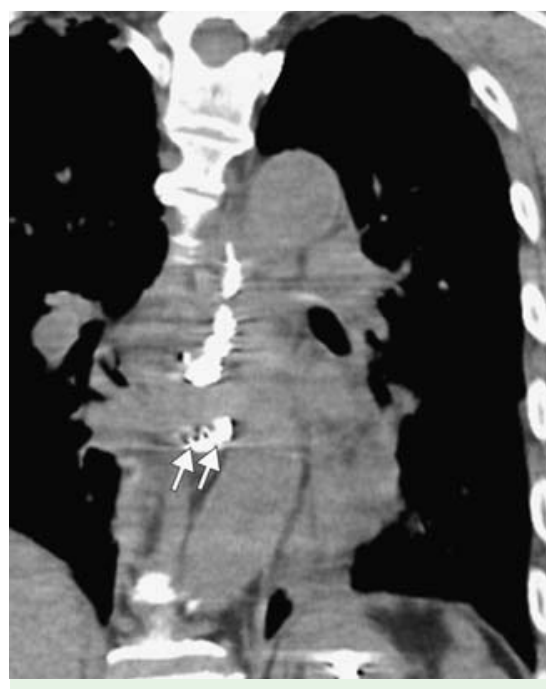

Fig. 4 Computed tomography (CT) scan after 2 days of treatment showing the over-thescope clip (OTSC; white arrows) closing the tear and the absence of pneumomediastinum and pleural effusion, suggesting complete sealing of the perforation site.

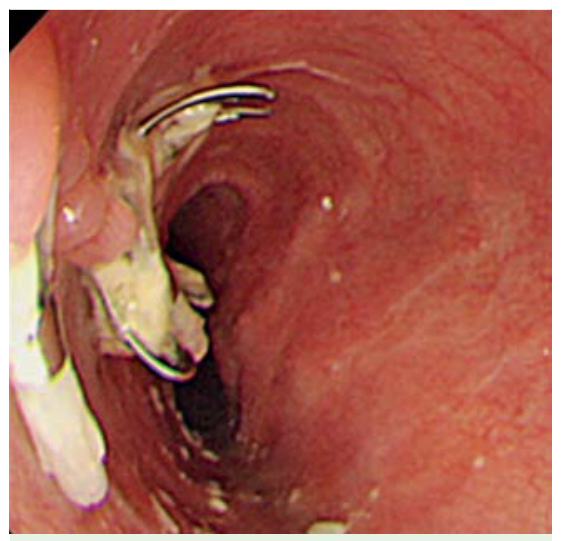

Fig. 5 Endoscopic view of the over-the-scope clip (OTSC) in situ and mucosal healing 24 days after treatment. out surgical intervention and associated complications. This case suggests that a multidisciplinary approach involving endoscopic placement of an OTSC is a suitable treatment option for Boerhaave syndrome.

Endoscopy_UCTN_Code_TTT_1AO_2AI

Competing interests: None

\section{H. Kobara' ${ }^{1}$ H. Mori ${ }^{1}$, K. Rafiq ${ }^{2}$,}

S. Fujihara', N. Nishiyama ${ }^{1}$, K. Kato', M. Oryu ${ }^{1}$, J. Tani ${ }^{1}$, H. Miyoshi ${ }^{1}$, T. Masaki ${ }^{1}$

${ }^{1}$ Department of Gastroenterology and Neurology, Faculty of Medicine, Kagawa University, Kagawa, Japan

2 Department of Pharmacology,

Faculty of Medicine, Kagawa University, Kagawa, Japan

\section{References}

1 Wolfson D, Barkin JS. Treatment of Boerhaave's syndrome. Curr Treat Options Gastroenterol 2007; 10: 71-77

2 Swinnen J, Eisendrath P, Rigaux J et al. Selfexpandable metal stents for the treatment of benign upper GI leaks and perforations. Gastrointest Endosc 2011; 73: 890-899
3 Gubler C, Bauerfeind P. Successful closure of an esophagopericardial fistula with an over-the-scope clip. Endoscopy 2012; 44 (Suppl. 02): E194 - 195

4 Traina M, Curcio G, Tarantino I et al. New endoscopic over-the-scope clip system for closure of a chronic tracheoesophageal fistula. Endoscopy 2010; 42 (Suppl. 02): E54-55

5 Mori H, Kobara H, Nishiyama $N$ et al. Rectal perforations and fistulae secondary to a glycerin enema: closure by over-the-scopeclip. World J Gastroenterol 2012; 18 : 3177-3180

Bibliography

DOI http://dx.doi.org/

10.1055/s-0032-1326454

Endoscopy 2014; 46: E82-E83

(c) Georg Thieme Verlag KG

Stuttgart $\cdot$ New York

ISSN 0013-726X

\section{Corresponding author}

\section{H. Kobara}

Department of Gastroenterology and Neurology Faculty of Medicine

Kagawa University

1750-1 Ikenobe, Miki, Kita

Kagawa 761-0793

Japan

Fax: +81-87-8912158

kobara@med.kagawa-u.ac.jp 